\title{
STRATEGI PENGEMBANGAN PARIWISATA BERBASIS MASYARAKAT (STUDI KASUS DI PERKAMPUNGAN WISATA SOUSU, KABUPATEN WAKATOBI)
}

\author{
Hidrawati $^{\left.1^{*}\right)}$, Sumiman Udu ${ }^{2)}$, Abdul Manan ${ }^{3)}$, Sariamin Sahari ${ }^{4)}$ Samsul Alam Fyka ${ }^{1)}$ \\ ${ }^{1} J u r u s a n$ Agribisnis Fakultas Pertanian Universitas Halu Oleo Kendari Indonesia 93232 \\ 2Jurusan Pendidikan Bahasa FKIP Universitas Halu Oleo Kendari Indonesia 93232 \\ ${ }^{3}$ Jurusan Kehutanan Fakultas Kehutanan dan IImu Lingkugan Universitas Halu Oleo Kendari Indonesia 93232 \\ ${ }^{4}$ Jurusan Ekowisata, Akademi Komunitas KKP RI Kabupaten Wakatobi, Indonesia \\ *Corresponding author : hidrawati@uho.ac.id \\ To cite this article: \\ Hidrawati, H., Udu, S., Manan, A., Sahari, S., \& Fyka, S. (2020). Strategi Pengembangan Pariwisata Berbasis \\ Masyarakat (Studi Kasus di Perkampungan Wisata Sousu, Kabupaten Wakatobi). Jurnal IImiah Membangun \\ Desa dan Pertanian, 5(3), 87 - 95. doi:http://dx.doi.org/10.37149/jimdp.v5i3.12028
}

Received: May 08, 2020; Accepted: June 22, 2020; Published: June 28, 2020

\begin{abstract}
This research is based on an effort to implement a community-based tourism approach, generally has the main objective to arrange strategy of community-based tourism development at tourism Sousu Rustic. Specifically, this research has a purpose to identify local characteristics that consist of internal and external elements of Sousu in developing tourism based on community. The research was conducted in March-October 2018 at Tourism Sousu Rustic Matahora Village, South of Wangi-Wangi District, Wakatobi Regency, Southeast Sulawesi. Data in this research consists of primer and secondary data collected by observation, interview, and focus group discussion techniques. The data analyzed qualitatively descriptively by using a matrix SWOT analysis tool and litmus test to identify the most strategy issue at Sousu Tourism development. The result of the research showed that the most strategic issues in Sousu tourism development consist of: community knowledge and skills improvement, funding to community tourism business support, minimize relocation community settlement issues and beach abrasion, and improve tourism exciting and does tourism promotion. To implement the strategies, it needs multi-collaboration between communities as the main actor, local government as a regulator, private sector as donor institution, and NGO as community facilitator.
\end{abstract}

Keywords: community based tourism; sousu; strategy; wakatobi;

\section{PENDAHULUAN}

Tulisan ini didasari oleh maraknya isu mengenai swastanisasi aset negara atau daerah. Terdapat beberapa kekayaan di negeri ini, misalnya potensi pariwisata lokal yang semestinya dikelola oleh negara atau masyarakat tetapi diambil alih oleh perusahaan asing (Andergassen \& Candela, 2013; Nurmansyah, 2014), baik yang berasal dari dalam maupun luar negeri. Pengelolaan oleh perusahaan asing seringkali menimbulkan permasalahan, misalnya terjadinya eksploitasi sumberdaya alam dan kesenjangan sosial ekonomi masyarakat (Drăgulănescu, Druţu, \& Sciences, 2012). Keuntungan terbesar dari bentuk pengelolaan tersebut biasaya diterima oleh pihak korporasi, sedangkan keuntungan terkecil termasuk implikasi negatifnya diterima oleh negara, terutama masyarakat yang berada di sekitar lokasi aset.

Demikian pula yang terjadi di Perkampungan Wisata Sousu. Hasil wawancara dan observasi pra penelitian menunjukkan bahwa Perkampungan wisata ini belum banyak dikunjungi oleh wisatawan mancaranegara, tetapi wisatawan nasional dan lokal lebih kurang 200 orang per minggu yang masuk ke lokasi ini. Masyarakat setempat belum memperoleh keuntungan yang optimal dari kehadiran wisatawan tersebut. Saat ini masyarakat masih memiliki pendapatan dengan rata-rata $\mathrm{Rp}$ 1.200.000,---per bulan yang umumnya diperoleh dari sektor nonpariwisata (BPS, 2018). Aspek penting lainnya yang mendorong untuk dilaksanakannya penelitian ini yaitu bahwa perkampungan wisata Sousu memiliki potensi pariwisata yang telah lama dikenal dan dimanfaatkan oleh masyarakat Wakatobi. Sousu mempunyai keindahan panorama pantai yang membujur di sepanjang 
perkampungan dengan pasir yang berwarna putih. Di sebelah barat dengan jarak lebih kurang $1,5 \mathrm{~km}$ terdapat pantai pulau Matahora yang tidak berpenghuni dengan luas lebih kurang 153 hektar. Dokumen RTRW Kabupaten Wakatobi tahun 2012-2032 menunjukkan bahwa kawasan perairan perkampungan Sousu Desa Matahora merupakan salah satu site penyelaman. Dari segi budaya, masyarakat tersebut memiliki beberapa bentuk tradisi yang tertuang dalam upacara adat, tarian tradisional, permainan tradisional dan beberapa bentuk kearifan lokal, baik dalam bidang konservasi alam maupun dalam bidang pertanian (Hidrawati, 2019).

Strategi pengembangan pariwisata Sousu dalam penelitian ini didesain dengan pendekatan community based tourism (CBT). Pendekatan CBT menempatkan masyarakat sebagai pelaku utama melalui pemberdayaan masyarakat, sehingga kemanfaatan kepariwisataan sebesar-besarnya bagi masyarakat (Suganda, 2018). Pengembangan pariwisata berbasis masyarakat dapat meminimalisasi dampak negatif dari pengembangan pariwisata yang mengandalkan pihak luar, karena mengutamakan keterlibatan masyarakat baik dalam perencanaan, pelaksanaan, evaluasi dan pembagian hasil. Selain itu, pendekatan ini dipilih dalam penelitian ini karena hasil-hasil studi sebelumnya menunjukan bahwa pengembangan ekowisata dengan prinsip community based merupakan pola yang tepat untuk mengembangkan pariwisata di daerah (Drăgulănescu et al., 2012). Pembangunan pariwisata berbasis masyarakat dapat memberikan manfaat berupa peningkatan pendapatan masyarakat (Ahmad N.A.A., 2017; Sebele, 2010), dan mendukung pembangunan berkelanjutan (Chok, Macbeth, \& Warren, 2007; Lee \& Jan, 2019). Kajian ini tidak akan membahas sisi positif dari pendekatan community based sebagaimana dikemukakan oleh beberapa peneliti sebelumnya. Penelitian ini mengulas tentang suatu bentuk pengembangan pariwisata berbasis masyarakat, agar manfaat atau implikasi positif dari pendekatan tersebut dapat diperoleh masyarakat Sousu.

Berkaitan dengan beberapa keunggulan kompetitif pendekatan pembangunan pariwisata berbasis masyarakat dan dengan memperhatikan fenomena masyarakat Sousu, maka secara umum tujuan penelitian ini adalah mendesain strategi pengembangan pariwisata berbasis masyarakat di Perkampungan Wisata Sousu. Secara khusus, penelitian ini bertujuan untuk mengetahui karakteristik lokal masyarakat yang termasuk dalam aspek lingkungan internal dan eksternal dalam pengembangan pariwisata. Hasil penelitian diharapkan dapat berguna sebagai bahan masukan bagi masyarakat, dan pemerintah dalam perumusan kebijakan untuk pengembangan sektor pariwisata Sousu. Hasil penelitian ini juga diharapkan dapat bermanfaat sebagai bahan referensi dan pembanding bagi peneliti selanjutnya.

\section{MATERI DAN METODE}

Penelitian ini dilaksanakan di perkampungan wisata Sousu, Desa Matahora Kecamatan Wangi-Wangi Selatan Kabupaten Wakatobi. Lokasi ini dipilih karena objek wisata di perkampungan tersebut telah lama dikenal dan dimanfaatkan oleh masyarakat. Selain itu, lokasi ini direncanakan oleh Pemerintah daerah sebagai situs pintu masuk wisatawan domestik dan mancanegara dalam pengembangan pariwisata Wakatobi di pusat segitiga karang dunia. Penelitian ini dilaksanakan sebagai bentuk upaya untuk mempersiapkan masyarakat dalam merespon peluang yang diciptakan oleh Pemerintah tersebut. Penelitian dilaksanakan pada bulan Maret-Oktober 2018.

Penelitian menggunakan metode campuran (mix method). Pendekatan kualitatif digunakan untuk mengungkap karakteristik lokal masyarakat Sousu, dan pendekatan kuantitatif untuk mendesain strategi pengembangan pariwisata Sousu. Penelitian dilakukan pada sebuah areal studi kasus, dengan tujuan untuk menyederhanakan lingkup penelitian, serta memudahkan proses perolehan data untuk merancang strategi pengembangan pariwisata. Data diperoleh melalui observasi, wawancara, dan diskusi kelompok terfokus (focus Group Discussion/FGD). Wawancara dilaksanakan dalam dua bentuk, yaitu:

1. Wawancara dengan menggunakan panduan pertanyaan pada 42 orang informan. Sampel Informan diambil sebanyak $10 \%$ dari 687 populasi yang terdiri dari 487 jiwa penduduk desa Matahora dan 200 orang dari rata-rata jumlah pengunjung per minggu selama 1 bulan pengamatan. Informan dari unsur masyarakat Desa Matahora ditentukan secara purposive dengan mempertimbangkan keterlibatan mereka dalam kegiatan pengembangan pariwisata, misalnya sebagai pemilik sarana wisata, nelayan yang memanfaatkan perairan di sekitar lokasi wisata, tokoh masyarakat (sara), aparat desa dan tokoh pemuda.

2. Wawancara dengan menggunakan kuisioner tes litmus pada 17 orang responden, yang berasal dari 3 orang unsur pemerintah daerah, 2 orang unsur Dewan Perwakilan Rakyat Daerah (DPRD) Kabupaten Wakatobi, 3 orang aparat desa, 2 orang pengurus lembaga masyarakat (sara), dan 7 
orang pemilik sarana wisata. Responden ditentukan dengan mempertimbangkan keterkaitan tugas/tanggungjawab dan peran dari setiap unsur dengan pengembangan pariwisata.

FGD dilaksanakan untuk memperoleh beberapa informasi dari kelompok masyarakat dalam satu waktu yang tidak dapat dikumpulkan melalui wawancara individu. Informasi yang dimaksud meliputi permasalahan umum yang dihadapi oleh masyarakat, solusi yang sudah dilakukannya, dan harapan (visi misi) masyarakat terhadap pengembangan objek wisata.

Data dianalisis dengan membuat pemaknaan dan pengklasifikasian berdasarkan tujuan penelitian. Klasifikasi data dilakukan untuk memberikan gambaran yang jelas mengenai karakteristik lokal perkampungan Sousu. Hasil uraian mengenai karakteristik lokal selanjutnya dianalisis lingkungan strategisnya yang merupakan analisis terhadap lingkungan eksternal dan internal. Penilaian lingkungan eksternal mengacu pada 3 kategori faktor, yaitu faktor politik, faktor sosial ekonomi dan faktor jaringan kerja. Penilaian lingkungan internal juga mengacu pada 3 kategori yaitu faktor sumberdaya (input), strategi sekarang (proses) dan kinerja (output). Penilaian terhadap lingkungan eksternal dan internal dilakukan dengan menggunakan matriks SWOT (Strengths, Opportunities, Weaknesses dan Threats). Matriks SWOT akan melahirkan sejumlah isu strategis yang dapat dilaksanakan dalam pengembangan pariwisata Sousu, dan untuk memilih isu-isu yang paling strategi maka digunakan instrumen tes litmus. Instrumen ini berfungsi untuk mengukur tingkat kestrategisan masing-masing isu dengan berpedoman pada 13 pertanyaan yang tersaji dalam kuisioner. Jawaban diberi nilai atau skor antara 1 sampai dengan 3 . Nilai 1 atau nilai terendah diberikan pada jawaban yang bersifat operasional, yang penyelesaiannya dapat dilakukan melalui kegiatan rutin. Nilai 2 menunjukan jawaban yang bersifat antara operasional atau stategis. Skor tertinggi atau nilai 3 menunjukan jawaban yang bersifat strategis, yang penyelesainnya memerlukan prioritas pemecahan.

\section{HASIL DAN PEMBAHASAN}

\section{Karakteristik Perkampungan Wisata Sousu}

Secara administrasi, komunitas Sousu menghuni salah satu pedusunan di desa Matahora Kecamatan Wangi-Wangi Selatan Kabupaten Wakatobi. Dusun Sousu terletak di sebelah utara Desa Matahora. Perkampungan ini memiliki jarak tempuh kurang lebih 1,3 km dari ibukota desa, dan berjarak lebih kurang $14 \mathrm{~km}$ dari ibukota Kecamatan Wangi-Wangi Selatan sehingga mudah diakses dari ibukota kecamatan maupun kabupaten.

Perkampungan wisata Sousu memiliki topografi tanah yang berpasir putih karena terletak di sepanjang bibir pantai Sousu. Panjang garis pantai mencapai $1,8 \mathrm{~km}^{2}$ dengan luas wilayah $4,68 \mathrm{~km}^{2}$. Sementara itu, pada sisi yang lain terdapat lahan pertanian masyarakat yang berada di area berbukit dengan komposisi batu bertanah ${ }^{1}$. Para petani membudidyakan tanaman pangan seperti ubi kayu, jagung dan umbi-umbian lainnya serta aneka jenis buah dan sayuran tropis. Kegiatan bercocok tanam dilaksanakan dengan mengap likasikan pengetahuan lokal masyarakat untuk memanipulasi keterbatasan sumberdaya lahan (A. M. Kandari, 2017). Sistim bercocok tanam ini dapat menjadi salah satu objek daya tarik wisata (Ainley \& Smale, 2010; Junaedi, 2018; Nugroho, 2011). Lingkungan Sousu banyak ditumbuhi pohon kelapa dengan jarak tanam yang relatif teratur. Keteraturan ini sangat erat kaitannya dengan fungsi sosial dari tanaman kelapa yakni sebagai tapal batas kepemilikan tanah.

Perkampungan wisata Sousu di huni oleh 487 jiwa dan 131 KK (kantor Desa Matahora, 2019). Data Kantor Desa Matahora juga menyebutkan bahwa Dari keseluruhan jumlah penduduk Sousu, hanya 4 orang yang berijazah Diploma/Sarjana, 28 orang tamatan SLTA, 68 orang tamatan SLTP, 223 orang tamatan SD, 110 orang tidak tamat SD dan 54 orang yang tidak menempuh pendidikan formal. Menjadi petani dan nelayan adalah dua profesi yang umumnya disandang oleh satu orang kepala keluarga. Kegiatan pertanian dan mencari hasil laut dilaksanakan secara subsisten dengan menerapkan teknik-teknik kearifan lokal masyarakat, misalnya tondapa ${ }^{2}$ dan ou laro ${ }^{3}$ dalam bidang perikanan, dan heresoi ${ }^{4}$ dan weli'a ${ }^{5}$ dalam sistem pertanian. Masyarakat setempat juga memiliki keterampilan pertukangan kayu dan bangunan, berdagang, memelihara ternak seperti ayam, itik dan kambing.

\footnotetext{
${ }^{1}$ Batu bertanah merupakan istilah yang menggambarkan komposisi tanah pertanian di Kabupaten Wakatobi (A. M. Kandari, 2017; Rudi, 2016)

2 Tondapa merupakan suatu aturan dalam pengelolaan wilayah laut yang ditetapkan oleh Sara

${ }^{3}$ Ou laro merupakan wilayah atau zona tertentu yang diatur oleh Sara dalam mengelola Laut

4 Heresoi merupakan suatu teknik mengelola lahan pertanian dengan cara mengambil sampah rumah tangga atau seresah tanaman di sekitar ladang untuk dijadikan pupuk organic

${ }^{5}$ Weli'a adalah salah suatu teknik budidaya tanaman pada tahap pembukaan lahan
} 
Desa Matahora memiliki fasilitas pendidikan dan kesehatan serta fasilitas sosial ekonomi lainnya yang dimanfaatkan oleh masyarakat desa dan beberapa wilayah lainnya di sekitarnya. Di kawasan Desa Matahora juga terdapat beberapa fasilitas yang dapat mendukung pengembangan pariwisata di wilayah tersebut. Fasilitas yang dimaksud yakni Bandara Udara Wakatobi, 2 buah resort dan convention center, dan 2 lembaga pendidikan yang bertaraf nasional (Pondok Pendidikan Muaz Bin Jabal dan Akademi Komutas KKP RI). Ketersediaan fasilitas ini dapat mendukung pengembangan pariwisata, sebagaimana dikemukakan oleh (Sunaryo, 2013) bahwa fasilitas pendukung pariwisata dapat berupa fasilitas sosial seperti sarana pendidikan dan kesehatan, serta fasilitas transportasi.

\section{Analisis Lingkungan Internal dan Eksternal Pengembangan Pariwisata}

Berdasarkan hasil analisis terhadap karakteristik lokal dalam pengembangan pariwisata Sousu, maka diketahui bahwa secara internal terdapat aspek sumberdaya yang meliputi keadaan potensi sumberdaya alam (SDA), sumberdaya manusia (SDM), dana/anggaran, sarana dan prasarana, dan kelembagaan lokal. Aspek proses terkait dengan beberapa kegiatan yang telah dilakukan oleh masyarakat untuk mengembangkan pariwisata misalnya meminimalisasi laju abrasi di kawasan pantai Sousu, dan mengelola kawasan wisata secara sederhana. Aspek kinerja (output) merupakan hasil-hasil yang telah dicapai masyarakat berdasarkan usaha-usaha yang telah dilakukannya yaitu terbangunnya talut pemecah ombak, ditetapkannya peraturan pengelolaan dan penambangan pasir, dan dibangunnya beberapa sarana prasarana pariwisata. terdiri dari:

Secara eksternal, faktor politik yang berpengaruh terhadap pengembangan pariwisata Sousu

1. Komitmen Pemkab Wakatobi yang tertuang dalam visinya untuk menempatkan sektor pariwisata sebagai salah satu leading sektor pembangunan daerahnya;

2. Adanya Rencana Induk Pengembangan Pariwisata Daerah (Rippda) Kabupaten Wakatobi 20162025, yang didalamnya termuat bahwa Perkampungan Wisata Sousu merupakan salah satu site pariwsata yang teringterasi dengan lokasi pariwisata lainnya;

3. Berlakunya Peraturan Pemerintah No. 72 Tahun 2005 tentang pemerintahan desa, yang memberikan ruang otonom bagi desa dalam mengembangkan wilayahnya sesuai dengan potensinya;

4. Adanya isu relokasi masyarakat Sousu yang rentan terhadap konflik, yang didasari oleh rencana pemerintah (tidak tertulis) untuk merelokasi wilayah di kawasan tersebut karena seluruh wilayahnya akan dijadikan lokasi objek wisata.

Faktor sosial ekonomi meliputi:

1. Terjadinya peningkatan jumlah pengunjung dari waktu ke waktu. Pada saat penelitian ini berlangsung, diestimasi rata-rata pengunjung 200 orang per minggu. Jumlah ini diprediksi akan terus meningkat seiring dengan peningkatan minat masyarakat untuk berwisata;

2. Adanya beberapa lokasi wisata bahari yang baru seperti Pantai Waikesa, Pantai Waha, dan Pantai Cemara yang juga sedang mengalami situasi pengembangan;

3. Meningkatnya minat masyarakat dari luar Sousu untuk mengelola potensi pariwisata yang ada, melalui permintaan pembeliaan lahan di sekitar kawasan objek wisata;

4. Kawasan pantai Sousu yang rawan terhadap abrasi, sebagai implikasi dari letak geografis Sousu yang berbatasan langsung dengan Laut Banda serta adanya kegiatan illegal penambangan pasir.

Faktor Jaringan kerja (networking) yang berpengaruh terhadap pengembangan pariwisa Sousu yaitu adanya beberapa instansi pemerintah serta lembaga nonpemerintah yang berada di tingkat lokal, nasional maupun internasional yang menjadikan perkampungan Wisata Sousu sebagai salah satu sasaran kegiatan pengembangan masyarakat.

Hasil penilaian lingkungan internal dan eksternal sebagaimana tampak pada Tabel 1 menunjukkan bahwa karakteristik lokal yang berpengaruh dalam pengembangan pariwisata Sousu terbagi atas 4 faktor kekuatan, 4 faktor kelemahan, 5 faktor peluang dan 4 faktor ancaman. Faktor kekuatan yang dimaksud yaitu mempunyai potensi pariwisata yang menarik; adanya kelembagaan masyarakat dengan sistem sara; adanya minat masyarakat untuk mengembangkan lokasi pariwisata; dan adanya kemudahan untuk mengakses lokasi wisata. Faktor kekuatan yang bersumber dari kondisi sumberdaya alam merupakan salah satu faktor internal utama dalam pengembangan objek wisata (Pomantow, 2013). Faktor kekuatan dalam analisis SWOT dapat digunakan untuk memanfaatkan peluang sekaligus menghindari ancaman (Gürel \& Tat, 2017). Salah satu peluang yang dapat dimanfaatkan yaitu komitmen pemkab dalam pengembangan pariwisata Sousu, sekaligus untuk menghindari ancaman berupa adanya isu relokasi masyarakat. Komitmen pemerintah yang 
tertuang dalam suatu peraturan dapat menjadi peluang yang dapat dimanfaatkan dalam pengembangan objek wisata (Barreto \& Giantari, 2015). Pemerintah Kabupaten Wakatobi memiliki komitmen dalam pengembangan pariwisata yang antara lain diwujudkan melalui ditetapkannya RIPPDA. Hal ini juga diperkuat dengan adanya peraturan Pemerintah (PP) Nomor 72 Tahun 2005 yang memberi ruang secara otonom kepada desa untuk mengelola potensi alamnya, termasuk potensi pariwisata.

Tabel 1. Rekapitulasi hasil penilaian lingkungan internal dan eskternal

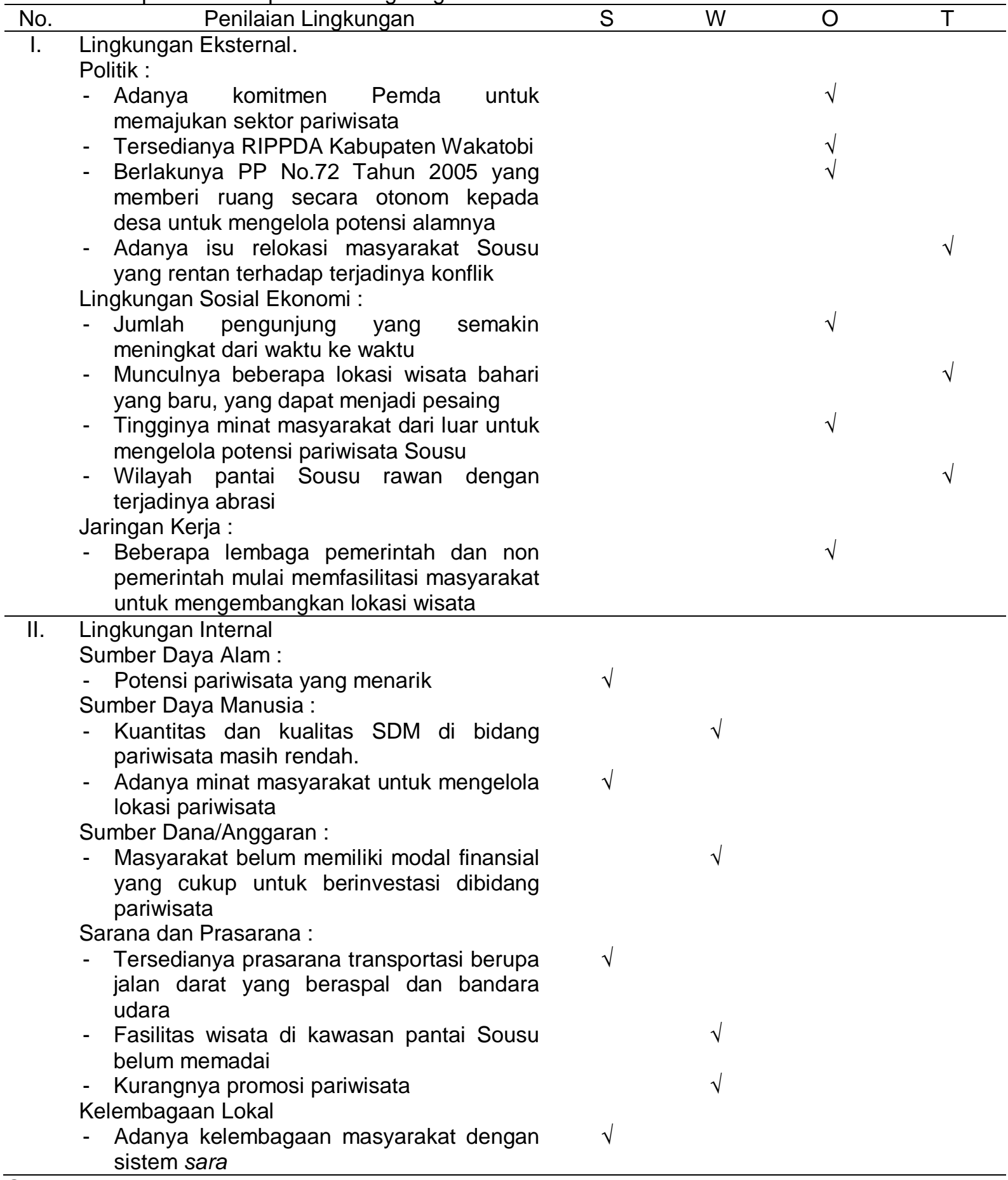

Sumber: Data Primer diolah, 2019 


\section{Strategi Pengembangan Pariwisata}

Tabel 2. Matriks SWOT strategi pengembangan pariwisata Sousu

\begin{tabular}{|c|c|c|}
\hline & & \\
\hline Faktor Eksternal & $\begin{array}{l}\text { Opportunities } \\
\text { - Adanya komitmen Pemda } \\
\text { untuk memajukan sektor } \\
\text { pariwisata } \\
\text { - Adanya RIPPDA Wakatobi } \\
\text { Tahun } 2008 \\
\text { - Berlakunya PP No.72 } \\
\text { Tahun } 2005 \text { yang memberi } \\
\text { ruang secara otonom } \\
\text { kepada desa untuk } \\
\text { mengelola potensi alamnya } \\
\text { - Beberapa lembaga } \\
\text { pemerintah dan non } \\
\text { pemerintah mulai } \\
\text { memfasilitasi masyarakat } \\
\text { untuk mengembangkan } \\
\text { lokasi wisata } \\
\text { - Jumlah pengunjung yang } \\
\text { semakin meningkat }\end{array}$ & $\begin{array}{l}\text { Threats } \\
\text { - Adanya isu relokasi } \\
\text { masyarakat Sousu yang } \\
\text { rentan terhadap terjadinya } \\
\text { konflik } \\
\text { - Munculnya beberapa lokasi } \\
\text { wisata bahari yang baru, } \\
\text { yang dapat menjadi pesaing } \\
\text { pariwisata Sousu } \\
\text { - Kawasan pantai di } \\
\text { sepanjang perkampungan } \\
\text { Sousu rawan terhadap } \\
\text { terjadinya abrasi } \\
\text { - Tingginya minat masyarakat } \\
\text { dari luar untuk mengelola } \\
\text { potensi pariwisata Sousu }\end{array}$ \\
\hline $\begin{array}{l}\text { Strengths } \\
\text { - Mempunyai potensi pariwisata } \\
\text { yang menarik } \\
\text { - Adanya kelembagaan } \\
\text { masyarakat dengan sistem sara } \\
\text { - Adanya minat masyarakat untuk } \\
\text { mengembangkan lokasi } \\
\text { pariwisata } \\
\text { - Adanya kemudahan untuk } \\
\text { mengakses lokasi wisata } \\
\text { karena tersedia jalan darat yang } \\
\text { beraspal dan bandara udara }\end{array}$ & $\begin{array}{l}\text { Isu-Isu Strategi S-O } \\
\text { - Menggunakan potensi } \\
\text { pariwisata dan minat } \\
\text { masyarakat } \\
\text { memanfaatkan kebijakan } \\
\text { Pemda } \\
\text { - Menggunakan } \\
\text { kelembagaan sara untuk } \\
\text { mempermudah proses } \\
\text { pendampingan oleh } \\
\text { beberapa lembaga yang } \\
\text { ada } \\
\text { - Menggunakan potensi } \\
\text { pariwisata dan kemudahan } \\
\text { mengakses lokasi wisata } \\
\text { untuk meningkatkan jumlah } \\
\text { penquniung }\end{array}$ & $\begin{array}{l}\text { Isu-Isu Strategi S-T } \\
\text { - Memanfaatkan kelembagaan } \\
\text { sara untuk meredam isu } \\
\text { relokasi dan meminimalisasi } \\
\text { abrasi pantai } \\
\text { - Memanfaatkan minat } \\
\text { masyarakat untuk } \\
\text { mengembagkan daya tarik } \\
\text { wisata dalam mengatasi } \\
\text { persaingan usaha pariwisata } \\
\text { - Memanfaatkan kelembagaan } \\
\text { sara dan minat masyarakat } \\
\text { untuk menekan masyarakat } \\
\text { luar yang ingin mengelola } \\
\text { potensi pariwisata }\end{array}$ \\
\hline $\begin{array}{l}\text { Weaknesses } \\
\text { - Rendahnya kualitas dan } \\
\text { kuantitas sumberdaya manusia } \\
\text { di bidang pariwisata } \\
\text { - Masyarakat belum memiliki } \\
\text { modal finansial yang cukup } \\
\text { untuk berinvestasi di bidang } \\
\text { pariwisata } \\
\text { - Fasilitas wisata di kawasan } \\
\text { pantai Sousu tidak memadai } \\
\text { - Kurangnya promosi wisata }\end{array}$ & $\begin{array}{l}\text { Isu-Isu Strategi } W-O \\
\text { - Menanggulangi rendahnya } \\
\text { kualitas dan kuantitas SDM } \\
\text { dengan memanfaatkan } \\
\text { proses pendampingan } \\
\text { - Menanggulangi kurangnya } \\
\text { modal finansial dan tidak } \\
\text { memadainya sarana } \\
\text { prasarana wisata, dengan } \\
\text { memanfaatkan kebijakan } \\
\text { Pemda dan kerjasama } \\
\text { dengan beberapa lembaga } \\
\text { yang ada } \\
\text { - Menanggulangi kurangnya } \\
\text { promosi pariwisata dengan } \\
\text { memanfaatkan kebijakan } \\
\text { Pemda }\end{array}$ & $\begin{array}{l}\text { Isu-Isu Strategi } W-T \\
\text { - Menanggulangi rendahnya } \\
\text { kualitas dan kuantitas SDM } \\
\text { serta menghindari adanya } \\
\text { isu relokasi dan abrasi } \\
\text { pantai } \\
\text { - Menanggulangi kurangnya } \\
\text { modal dan tidak } \\
\text { memadainya wisarana dan } \\
\text { prasarana wisata minat } \\
\text { menghindari luar untuk } \\
\text { masyarakat luar } \\
\text { mengelola pariwisata Sousu } \\
\text { - Menanggulangi kurangnya } \\
\text { promosi pariwisata dan } \\
\text { menghindari persaingan }\end{array}$ \\
\hline
\end{tabular}

Sumber: Data Primer diolah, 2019 
Tabel 3. Rekapitulasi hasil tes litmus

\begin{tabular}{|c|c|c|c|c|c|c|c|c|c|c|c|c|c|c|c|c|}
\hline \multirow[t]{2}{*}{$\begin{array}{l}\text { Nomor Isu } \\
\text { Strategis }\end{array}$} & \multicolumn{13}{|c|}{$\begin{array}{l}\text { Rata-Rata Skor tiap Pertanyaan } \\
\text { dari } 32 \text { Responden }\end{array}$} & \multirow{2}{*}{$\begin{array}{l}\text { Jml } \\
\text { Skor }\end{array}$} & \multirow{2}{*}{$\begin{array}{c}\text { Skor } \\
\text { rata- } \\
\text { rata }\end{array}$} & \multirow{2}{*}{$\begin{array}{l}\text { Tingkat } \\
\text { Strategis }\end{array}$} \\
\hline & 1 & 2 & 3 & 4 & 5 & 6 & 7 & 8 & 9 & 10 & 11 & 12 & 13 & & & \\
\hline 1 & 1 & 3 & 1 & 1 & 1 & 1 & 3 & 3 & 3 & 3 & 2 & 2 & 1 & 25 & 1,92 & $S$ \\
\hline 2 & 1 & 3 & 1 & 1 & 1 & 1 & 3 & 1 & 3 & 3 & 1 & 2 & 2 & 23 & 1,77 & $S$ \\
\hline 3 & 1 & 3 & 2 & 3 & 1 & 1 & 3 & 3 & 3 & 3 & 1 & 2 & 2 & 28 & 2,15 & $S$ \\
\hline 4 & 1 & 3 & 1 & 1 & 1 & 3 & 3 & 3 & 3 & 3 & 1 & 3 & 3 & 29 & 2,23 & $S$ \\
\hline 5 & 1 & 3 & 2 & 3 & 3 & 1 & 3 & 3 & 2 & 3 & 1 & 2 & 1 & 28 & 2,15 & $S$ \\
\hline 6 & 1 & 3 & 1 & 3 & 1 & 3 & 1 & 1 & 3 & 3 & 1 & 2 & 3 & 26 & 2,00 & $S$ \\
\hline 7 & 1 & 3 & 2 & 3 & 3 & 1 & 3 & 3 & 3 & 3 & 3 & 2 & 3 & 33 & 2,54 & SS \\
\hline 8 & 1 & 3 & 3 & 3 & 2 & 3 & 3 & 3 & 3 & 3 & 3 & 3 & 1 & 37 & 2,85 & SS \\
\hline 9 & 1 & 3 & 2 & 3 & 3 & 3 & 1 & 1 & 2 & 3 & 3 & 3 & 1 & 29 & 2,23 & $S$ \\
\hline 10 & 1 & 3 & 3 & 3 & 3 & 3 & 3 & 3 & 3 & 3 & 3 & 3 & 1 & 38 & 2,92 & SS \\
\hline 11 & 1 & 3 & 3 & 3 & 3 & 1 & 3 & 3 & 2 & 3 & 3 & 2 & 3 & 33 & 2,54 & SS \\
\hline 12 & 1 & 2 & 3 & 3 & 3 & 1 & 3 & 3 & 2 & 3 & 3 & 3 & 1 & 31 & 2,38 & SS \\
\hline
\end{tabular}

Sumber: Data Primer diolah, 2019

Keterangan : SS=Sangat Strategis; $\mathrm{S}=$ Strategis

Berdasarkan hasil analisis matriks SWOT maka diperoleh 12 isu-isu strategis sebagaimana tampak pada Tabel 2. Isu-isu tersebut kemudian diuji menggunakan tes litmus untuk mengetahui isu yang paling strategis atau isu yang lebih prioritas. Hasil uji test litmus (Tabel 3) menghasilkan 7 isu yang memiliki kategori 'strategis', dan 5 isu yang tergolong 'sangat strategis'. Kelima isu yang 'sangat strategis' yaitu:

1. Menanggulangi kurangnya pengetahuan dan keterampilan masyarakat dengan memanfaatkan proses pendampingan

2. Menanggulangi kurangnya modal finansial dan tidak memadainya sarana prasarana wisata dengan memanfaatkan kebijakan pemda, serta kerjasama dengan beberapa lembaga yang ada

3. Menanggulangi tidak memadainya keterampilan dan pengetahuan masyarakat serta menghindari adanya isu relokasi dan abrasi pantai

4. Menanggulangi tidak cukupnya modal dan tidak memadainya sarana prasarana wisata, serta menghindari keinginan masyarakat luar untuk mengelola potensi pariwisata Sousu

5. Menanggulangi kurangnya promosi pariwisata dan menghindari persaingan usaha pariwisata.

Kelima isu 'sangat strategis' tersebut akan dikelola atau direalisasikan sebagaimana mekanisme dalam proses perencanaan strategis. Pengelolaan isu bertujuan untuk mengambarkan secara detail strategi-strategi yang dapat ditempuh dalam menyelesaikan isu strategis yang ada, agar isu tidak hanya sekedar isu, tetapi ada upaya realisasinya. Upaya realisasi dirumuskan dalam bentuk strategi pengembangan pariwisata berbasis masyarakat yang didasarkan pada pertimbangan ketersediaan sumberdaya dalam pelaksanaanya; dan kemudahan dalam pelaksanaan strategi untuk mencapai tujuan. Strategi yang dimaksud meliputi:

1. Meningkatkan pengetahuan dan keterampilan masyarakat dalam bidang pariwisata;

2. Meningkatkan ketersediaan modal finansial bagi usaha pariwisata;

3. Meredam isu relokasi dan meminimalisasi laju abrasi pantai; dan

4. Meningkatkan daya tarik wisata dan promosi pariwisata;

Upaya meningkatkan pengetahuan dan keterampilan masyarakat dalam bidang pariwisata perlu dilakukan sebagai strategi utama dalam pengembangan pariwisata Sousu. Masyarakat membutuhkan pengetahuan dan keterampilan dalam mengelola pariwisata (Morrison, 2018). Peningkatan kapasitas masyarakat disekitar lokasi objek wisata dapat dilakukan antara lain melalui pemberian pelatihan dan studi banding (Noho, 2014). Masyarakat juga memerlukan pendampingan untuk meningkatkan kapasitanya dalam mengelola kawasan objek wisata (Dangi \& Jamal, 2016). Pendampingan dapat diperoleh dari lembaga pemerintah ataupun nonpemerintah, sehingga masyarakat dapat memanfaatkan peluang terjalinnya kerjasama pemerintah dengan lembagalembaga tersebut. Kerjasama ini juga dibutuhkan untuk melaksanakan strategi peningkatan ketersediaan modal usaha, meredam isu relokasi dan meningkatkan promosi pariwisata.

Kerjasama atau lebih tepat disebut sebagai kolaborasi dapat dilakukan antara masyarakat, pemerintah, lembaga nonpemerintah dan pengusaha swasta. Pendekatan kolaborasi dibutuhkan untuk meningkatkan keberdayaan masyarakat dalam mengelola potensi alamnya secara optimal (Graci, 2013). Pengembangan pariwisata berbasis masyarakat membutuhkan kolaborasi dari berbagai pihak (Del Chiappa, Atzeni, \& Ghasemi, 2018; Tolkach \& King, 2015), karena masing- 
masing pihak memiliki kelemahan dan kekuatan untuk berinteraksi sesuai peranannya (Saito \& Ruhanen, 2017). Sistem kerjasama multi pihak memungkinkan masyarakat dapat menanggulangi kelemahannya dengan memanfaatkan peluang dari pihak lain. Pemanfaatkan kekuatan yang dimiliki masyarakat perlu merespon peluang dari pihak lain, seperti pemerintah dan lembaga-lembaga lainnya. Demikian pula untuk menanggulangi kelemahan dan menghindari ancaman, diperlukan sejumlah kekuatan dan kelemahan yang dapat bersumber dari berbagai pihak. Pada tatanan kolaborasi multipihak, masing-masing pihak berperan sesuai dengan unsur kekuatan yang dimilikinya (Jiang \& Ritchie, 2017). Masyarakat adalah pelaku utama yang beperan sebagai pengelola. Pemerintah berperan dalam menetapkan regulasi pengembangan pariwisata berbasis masyarakat. Pengusaha swasta berperan sebagai donatur dan lembaga nonpemerintah berperan sebagai pendamping atau fasilitator. Bila terjadi dominasi peran masyarakat dalam pengembangan pariwisata Sousu, maka konsep community based tourism dapat diwujudkan dengan baik.

\section{KESIMPULAN DAN SARAN}

Hasil identifikasi terhadap karakteristik lokal menunjukan bahwa secara internal, faktor-faktor yang berpengaruh terhadap pengembangan pariwisata berbasis masyarakat meliputi aspek input, proses dan output seperti keadaan potensi sumberdaya alam (SDA), sumberdaya manusia (SDM), dana/anggaran, sarana dan prasarana, serta kelembagaan lokal. Secara eksternal, terdapat faktor politik, ekonomi dan jaringan kerja antara lain adanya komitmen Pemkab Wakatobi dalam pengembangan objek wisata, terjadinya peningkatan jumlah pengunjung, dan kawasan pantai yang rawan abrasi. Berdasarkan hasil analisis SWOT dan tes litmus diketahui bahwa terdapat empat strategi utama dalam pengembangan objek wisata Sousu yaitu (1)meningkatkan pengetahuan dan keterampilan masyarakat; (2)meningkatkan ketersediaan modal finansial bagi usaha pariwisata; (3)meredam isu relokasi dan meminimalisasi laju abrasi pantai; dan (4)meningkatkan daya tarik wisata dan promosi pariwisata.

Berdasarkan hasil penelitian ini, maka disarankan kepada masyarakat agar dapat berkolaborasi dengan berbagai pihak seperti pemerintah, lembaga nonpemerintah (LSM) dan pengusaha swasta dalam mengembangkan pariwisata Sousu. Pada pola kolaborasi tersebut, masyarakat adalah pelaku utama yang bertindak sebagai pengelola, pemerintah daerah sebagai regulator, sektor swasta sebagai lembaga donor dan Lembaga nonpemerintah sebagai fasilitator masyarakat.

\section{REFERENSI}

A. M. Kandari, U. R., R. Marsuki Iswandi \& Nur Arafah. (2017). Local Wisdom as Adaptation Strategy in Suboptimal Land Management at Binongko Island, Wakatobi Indonesia. 14(1), 129.

Ahmad N.A.A., N. A. A. M. (2017). Community Based Tourism: Understanding, Benefits and Challenges. Anuar and Sood. Journal Tourism Hosiptallity. doi:10.4172/2167-0269.1000263

Ainley, S., \& Smale, B. (2010). A profile of Canadian agritourists and the benefits they seek. 5(1).

Andergassen, R., \& Candela, G. (2013). Less developed countries, tourism investments and local economic development. Review of Development Economics Journal, 17(1), 16-33.

Barreto, M., \& Giantari, I. K. (2015). Strategi Pengembangan Objek Wisata Air Panas Di Desa Marobo, Kabupaten Bobonaro, Timor Leste. E-Jurnal Ekonomi dan Bisnis Universitas Udayan.

BPS. (2018). Wakatobi Dalam AngkaTahun 2018, Wakatobi Regency in Figure 2018. In B. K. Wakatobi (Ed.), (Vol. 74070.1803). Wakatobi: Badan Pusat Statistik Kabupaten Wakatobi.

Chok, S., Macbeth, J., \& Warren, C. J. C. i. i. T. (2007). Tourism as a tool for poverty alleviation: A critical analysis of 'pro-poor tourism'and implications for sustainability. 10(2-3), 144-165.

Dangi, T. B., \& Jamal, T. (2016). An integrated approach to "sustainable community-based tourism". Journal Sustainability, 8(5), 475.

Del Chiappa, G., Atzeni, M., \& Ghasemi, V. (2018). Community-based collaborative tourism planning in islands: A cluster analysis in the context of Costa Smeralda. Journal of Destination Marketing

Management, 8, 41-48.

Drăgulănescu, I.-V., Druţu, M. J. I. J. o. A. R. i. A., Finance, \& Sciences, M. (2012). Rural tourism for local economic development. 2(1), 196-203.

Graci, S. (2013). Collaboration and partnership development for sustainable tourism. Journal Tourism Geographies, 15(1), 25-42. 
Gürel, E., \& Tat, M. (2017). SWOT analysis: a theoretical review. Journal of International Social Research 10(51).

Hidrawati, M. A. L., Nur Arafah, Samsul Alam Fyka dan Harviyaddin. (2019). Heresoi : The Action of Agriculture Land Conservation by Wangi-Wangi Island Community. Paper presented at the ICEASD 2019, Kendari-Indonesia.

Jiang, Y., \& Ritchie, B. W. (2017). Disaster collaboration in tourism: Motives, impediments and success factors. Journal of Hospitality Tourism Management, 31, 70-82.

Junaedi, I. G. B. R. U. I. W. R. (2018). Agrowisata Sebagai Pariwisata Alternatif Indonesia. Yogyakarta: Pendidikan Deepublish.

Lee, T. H., \& Jan, F.-H. (2019). Can community-based tourism contribute to sustainable development? Evidence from residents' perceptions of the sustainability. Journal Tourism management, 70, 368-380.

Morrison, A. M. (2018). Marketing and managing tourism destinations: Routledge.

Noho, Y. (2014). Kapasitas pengelolaan desa wisata religius bongo kabupaten gorontalo. Jurnal Nasional Pariwisata, 6(1), 8-21.

Nugroho, I. (2011). Ekowisata dan Pembangunan Berkelanjutan. Yogyakarta: Pustaka Pelajar.

Nurmansyah, A. (2014). Potensi Pariwisata dalam Perekonomian Indonesia. Jurnal Ekonomi Bisnis Dan Kewirausahaan, 3(1).

Pomantow, L. K., Veronica; Poli, Hanny; Rogi, Octavianus HA. (2013). Faktor-Faktor Internal Pengembangan Objek Wisata Pantai Lakban Kabupaten Minahasa Tenggara Sebagai Objek Wisata Andalan. Journal SABUA, 5(3), 142-156.

Rudi, L. (2016). Membangun Karakter Maritim Melalui Pelayaran: Belajar dari Pelaut Binongko. Paper presented at the Seminar Nasional "Graduate Forum 2016" yang diseleggarakan oleh Program Pascasarjana Universitas Islam Negeri (UIN) Sunan Kalijaga, Yogyakarta.

Saito, H., \& Ruhanen, L. (2017). Power in tourism stakeholder collaborations: Power types and power holders. Journal of Hospitality Tourism Management, 31, 189-196.

Sebele, L. (2010). Community-based tourism ventures, benefits and challenges: Khama rhino sanctuary trust, central district, Botswana. 31(1), 136-146.

Suganda, A. D. (2018). Konsep Wisata Berbasis Masyarakat. JI-ECONOMICS: A Research Journal on Islamic Economics, 4(1), 29-41.

Sunaryo, B. (2013). Kebijakan Pembangunan Destinasi Pariwisata : Konsep dan Aplikasinya di Indonesia. Jakarta: Gava Media.

Tolkach, D., \& King, B. (2015). Strengthening community-based tourism in a new resource-based island nation: Why and how? Journal Tourism management, 48, 386-398. 